\title{
Effect of Glucose on the Expression of CD24 Marker in Umbilical Cord- Derived Mesenchymal Stem Cells
}

\section{Rithika Rajendran, Febe Renjitha Suman*, Alan Mathew Punnoose, Sarah Kuruvilla and S Krishnakumar}

Department of Pathology, Sri Ramachandra Medical College and Research Institute, Porur, Chennai, India

\begin{abstract}
A cluster of Differentiation 24 (CD24) is considered as a marker of pancreatic progenitor cells in the mouse. In human embryonic stem cells, CD24+ cells expressed Pancreatic Duodenal Homeobox 1 (PDX1) and insulin after 1 -week culture. PDX1 is a transcription factor that is essential for pancreatic differentiation and beta cell maturation. These cells could provide a source for beta cell replacement. To define the proper culture conditions for Mesenchymal Stem Cells (MSCs) to differentiate into islet cells, the CD24 expression at the MSC level with various glucose concentrations may be helpful.
\end{abstract}

This research aims to study the expression of CD24 in MSCs derived from umbilical cord Wharton's jelly with varying concentrations of glucose in vitro.

MSCs were isolated by enzymatic digestion using standard protocols from umbilical cord Wharton's jelly with ethical approval. The MSCs were characterized by standard criteria. Pancreatic progenitor marker CD24 expression was analyzed at serial passages from passage 0 to passage 4. Passage 1 with maximum expression and passage 3 with lesser expression were chosen for culture with high glucose medium of $2 X(11.2 \mathrm{mmol}), 4 \mathrm{X}(25 \mathrm{mmol})$ and $8 \mathrm{X}$ glucose concentrations $(50 \mathrm{mmol})$ for 4 weeks. Flow cytometry for CD24 was performed for all the cell populations. A graded dose-dependent increase in CD24 expression was observed in passage 1. The expression of the marker was present but less in graded glucose with cells from passage 3. The possibility of CD24 expression being stimulated by glucose is evident though it warrants further research.

This study suggests that passage 1 MSCs with high glucose medium may be selected for further research on pancreatic islet development.

Keywords: CD24; Mesenchymal stem cells; Glucose

Abbreviations: CD24: Cluster of Differentiation 24; PDX1: Pancreatic Duodenal Homeobox 1; MSC: Mesenchymal Stem Cell; DM: Diabetes Mellitus; FBS: Fetal Bovine Serum

\section{Introduction}

Diabetes Mellitus (DM) is a chronic metabolic disease with high morbidity and significant mortality. The prevalence of DM is quite alarming with around 347 million people affected worldwide, the largest contributors to the disease load being India (65.1 million people affected in 2013) and China [1]. Though the prevalence in India of $9.1 \%$ is only marginally higher than the worldwide prevalence of $8.3 \%$ the massive population contributes to the disease load [1].

Though many drugs are available, insulin is the better choice to reduce blood sugar levels. Insulin administered through syringes and pumps is discharged at doses adjusted according to blood sugar levels estimated either once daily or once in two weeks. However, there occur periods of variation in glucose level at the cellular level which is responsible for long term complications. The only definitive treatment option is a source of islet cells which discharges human insulin according to the changing milieu in the body to maintain sugar levels. The difficulties encountered with islet allograft transplant are the availability of cadaver donor, need for immune suppressants, graft cell loss and autoimmunity [2-4]. Hence it is the need of the hour to manufacture islet cells in vitro to have a constant source of supply replacing the currently available therapeutic measures.

The development of in vitro islets requires a viable source of stem cells. The perinatal tissues which include umbilical cord and placenta are wasted every day in tons. They are rich sources of MSCs which are immunologically naive and obtaining consent is relatively easy, as these tissues are only discarded otherwise.

At the initial stage of the process, the MSCs have to be isolated. Though there are different protocols defined by researchers to isolate MSCs from the umbilical cord, no standardized protocol is available yet.

Currently, islets cultured from human stem cells are quite fragile and have a limited shelf life of only 72 hours $[5,6]$. Also, the characterization, culture, and storage protocols have to be standardized. By studying pancreatic progenitor cells and development pathways we may find methods to improve our culture and storage techniques [7,8]. Novel markers identify pancreatic precursor cells [9].

CD24 is cited as a marker of mouse pancreatic progenitor cells. CD24+ cells isolated from human embryonic stem cell-induced

*Corresponding author: Febe Renjitha Suman, Department of Pathology, Sri Ramachandra Medical College and Research Institute, Porur, Chennai, India, Tel: +919994081470; E-mail: johnjennerresearch@gmail.com

Received December 27, 2018; Accepted January 25, 2019; Published January 30, 2019

Citation: Rajendran R, Suman FR, Punnoose AM, Kuruvilla S, Krishnakumar S (2019) Effect of Glucose on the Expression of CD24 Marker in Umbilical CordDerived Mesenchymal Stem Cells. Stem Cell Res Ther 9: 444. doi: 10.4172/2157 7633.1000444

Copyright: (c) 2019 Rajendran R, et al. This is an open-access article distributed under the terms of the Creative Commons Attribution License, which permits unrestricted use, distribution, and reproduction in any medium, provided the original author and source are credited. 
Citation: Rajendran R, Suman FR, Punnoose AM, Kuruvilla S, Krishnakumar S (2019) Effect of Glucose on the Expression of CD24 Marker in Umbilical Cord-Derived Mesenchymal Stem Cells. Stem Cell Res Ther 9: 444. doi: 10.4172/2157-7633.1000444

Page 2 of 4

pluripotent cell expressed PDX1 and insulin after 1-week culture. Isolation and characterization of pancreatic progenitors namely CD24 predicted the expression of PDX1. These cells have been identified to secrete pancreatic hormones including insulin [10]. These cells could provide a source for beta cell replacement.

To define the proper culture conditions to retrieve cells differentiate into islet cells, the CD24 expression at the MSC level with various glucose concentration may be helpful.

\section{Aim}

To study the expression of CD24 in MSCs with varying concentrations of glucose in vitro.

\section{Materials and Methods}

This is a laboratory-based descriptive study conducted after approval of the Institutional Ethics Committee (IEC-NI/14/ MAR/39/22) and Institutional Committee for Stem Cell Research and Therapy (ICSCRT/14/MAR/15/13). The umbilical cord was collected from the mother without co-morbid illness and full-term uneventful pregnancy took up for elective Lower Segment Cesarian Section (LSCS) following written informed consent from both the parents.

The MSCs were isolated using enzymatic digestion. Briefly, the cord was minced and subjected to the action of trypsin and collagenase (both HiMedia Laboratories, India). Approximately $2 \times 10^{5}$ cells were plated in $75 \mathrm{~cm}^{2}$ culture flask (Tarson) with $12-15 \mathrm{ml}$ of culture media (Alpha Minimum Essential Medium (aMEM) (Lonza \#12-169F) with $10 \%$ Fetal Bovine Serum (FBS)). They were incubated in humidified conditions at $37^{\circ} \mathrm{C}$ with $5 \% \mathrm{CO}_{2}$. The cells were passaged at $80 \%-90 \%$ confluency. The cells were characterized by flow cytometry (positive for CD90, CD73, CD105 and negative for CD34, CD45, CD11b) and trilineage differentiation into adipocytes, osteocytes, and chondrocytes.
Pancreatic progenitor marker CD24 expression was analyzed at serial passages from passage 0 to passage 4 . Passage 1 with maximum expression and passage 3 with lesser expression were chosen for culture with high glucose medium.

The expanded MSCs were seeded in a six-well plate at a density of 4000 cells $/ \mathrm{cm}^{2}$. Cell culture medium (DMEM with $10 \%$ FBS and $1 \%$ antibiotics) was changed every 3 days.

At $70 \%$ confluency, the medium was removed and the cells washed twice with PBS.

The control wells were cultured in $2 \mathrm{ml}$ of cell culture medium (5.6 mmol glucose).

The test wells were cultured in $2 \mathrm{ml}$ of the high glucose culture medium of $2 \mathrm{X}(11.2 \mathrm{mmol}), 4 \mathrm{X}(25 \mathrm{mmol})$ and $8 \mathrm{X}$ glucose concentrations $(50 \mathrm{mmol})$.

The cells were maintained in culture at for $37^{\circ} \mathrm{C}$ and $5 \% \mathrm{CO}_{2}$ for 4 weeks. The medium was changed every 3 days. Cell morphology was observed using an inverted phase contrast microscope.

Flow cytometry for CD24 (Catalogue No. 311103; BioLegend) with control Mouse IgG1 $\kappa$ isotype (Catalogue No. 0107; BioLegend) was performed for all the cell populations.

\section{Results}

The MSCs harvested from umbilical cord showed 73 colonies/100 cells. The standard MSC markers were $>98 \%$ positive for CD105, CD90 and CD 73 and $<1 \%$ positive for CD $34, \mathrm{CD} 45, \mathrm{CD} 11 \mathrm{~b}$. the cells were differentiated into adipocytes, osteocytes, and chondrocytes and demonstrated using histochemical stains. By flow cytometry surface marker CD24 was expressed in all passages with least expression seen in P0 (19.5\%) and maximum expression was seen in P1 (71\%). Passage to
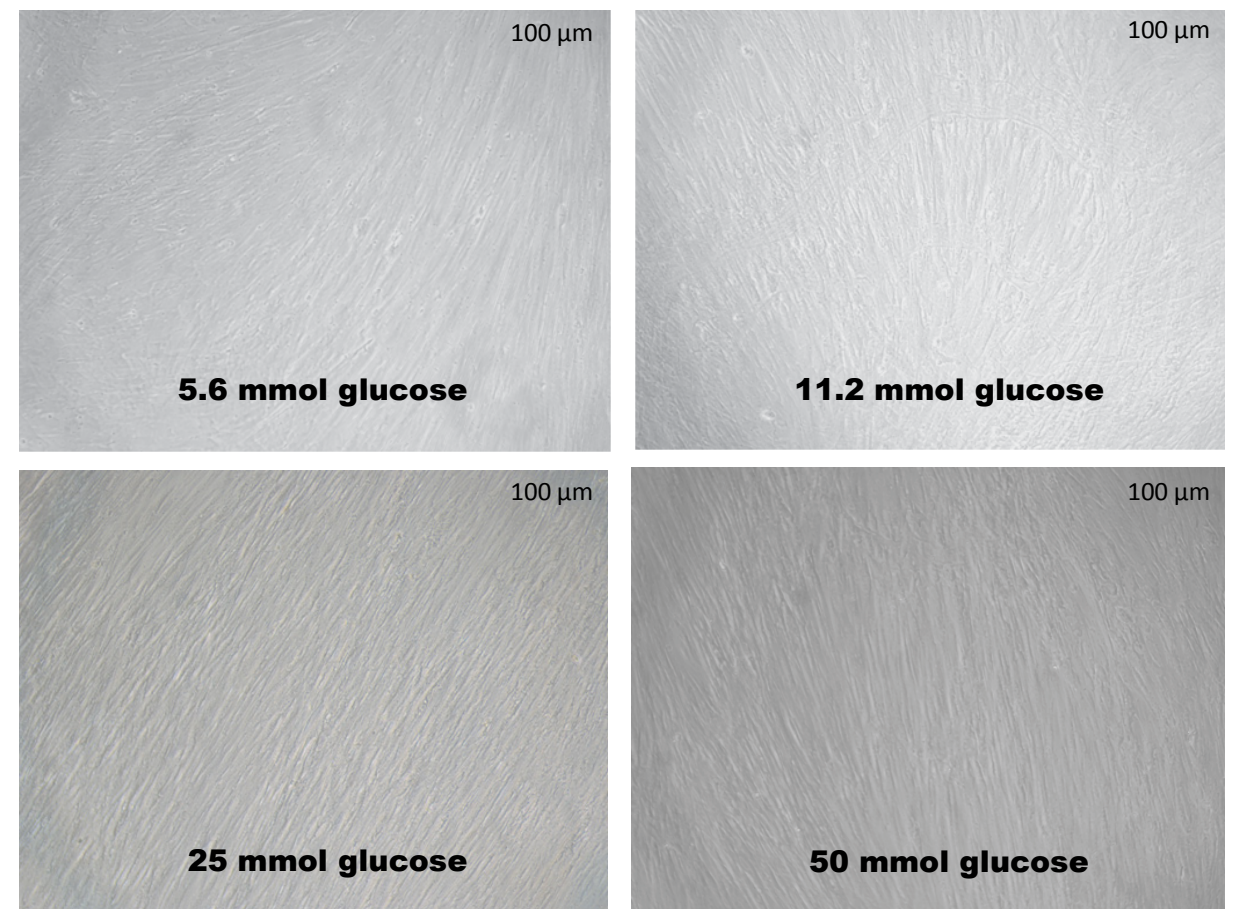

Figure 1: MSCs cultured in varying concentrations of glucose at 4 weeks (phase contrast microscope, 100X). 


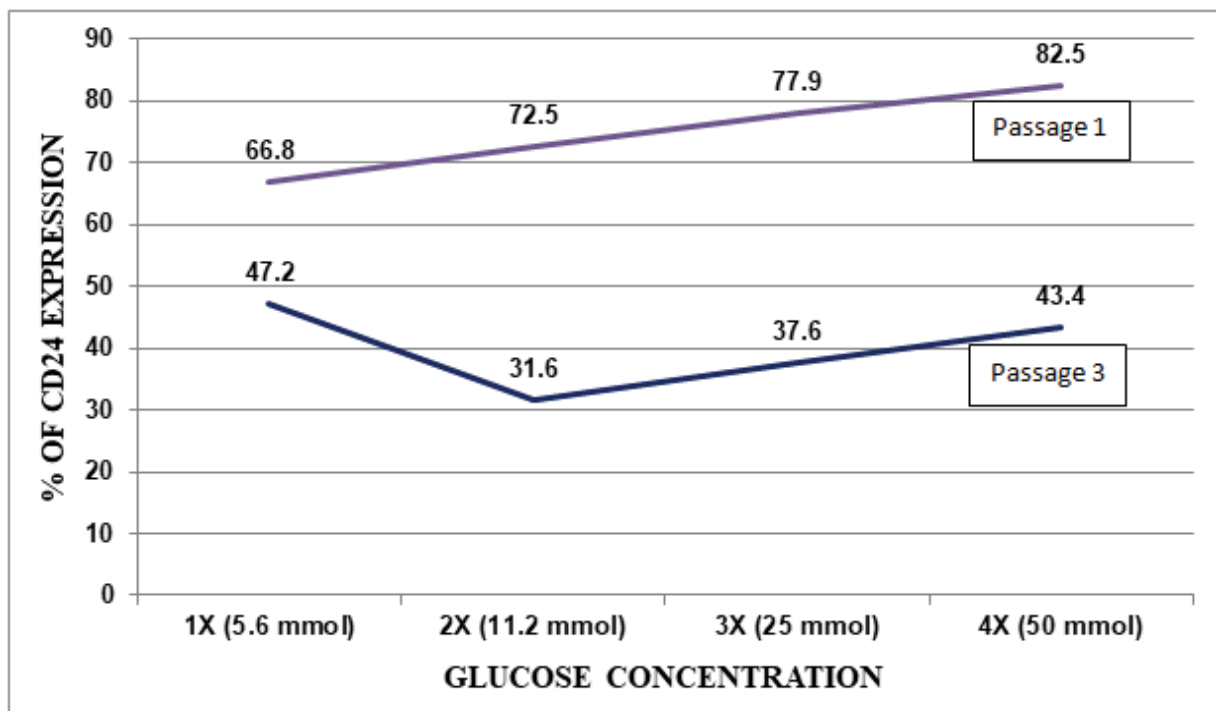

Figure 2: CD24 expression at different glucose concentrations.

P4 showed a graded fall in the expression of CD24. The MSCs survived in all the four concentrations of glucose and the same is shown in Figure 1. The cells were taken up for flow cytometry for CD24 and results are depicted in Figure 2. A graded dose-dependent increase in CD24 expression was observed in passage 1 . The expression of the marker was less in graded glucose with cells from passage 3.

\section{Discussion}

Based on the observations made in the present study and review of literature about other studies done so far, it seems that MSCs express CD24. These cells may develop into a clone of pancreatic progenitors, neural stem cells or cancer stem cells. This development depends on the environmental conditions and differentiating factors available.

It is known that elevated glucose concentrations impair cellular functions and induce apoptosis and is supposed to be the cause of further degeneration of pancreatic beta cells and all the long term complications in DM. It is hypothesized that high blood glucose levels also affect the body's native stem cells through mechanisms still under study. Controversial reports on the toxic effects of glucose on MSCs both in vivo and in vitro are available.

It had been reported by Stolzing, et al. [11] that high glucose is toxic to MSCs derived from rats while cell proliferation increased and the rate of apoptosis decreased when glucose concentration was reduced. $\mathrm{Li}$, et al. [12] cultured bone marrow-derived human MSCs in media containing 5, 6, 11, 25 and $40 \mathrm{mmol}$ concentration of glucose and measured the rate of proliferation and apoptosis. The inhibitory effect on cell apoptosis was noticed on short term exposure to high glucose medium but there was no effect on cell proliferation and apoptosis in long term cultures. Also Dhanasekaran, et al. [13] reported retention of MSC surface marker characteristics, proliferation, and differentiation potential in bone marrow and adipose-derived MSCs cultured at 25 mmol glucose concentration.

In the present study as CD24 expression was demonstrated in MSCs in all passages, this was used as a marker to observe the effect of glucose on MSCs. The cells were cultured for the long term in media with different glucose concentrations at passage 1 and passage 3 of
MSCs isolated from the third cord. It was found that CD24 expression in the cells was higher when cultured with higher glucose concentration in passage 1 and this expression was dose-dependent and graded. In passage 3 however, a drop and subsequent dose-dependent rise in the expression of CD24 was observed. The possibility of CD24 expression being stimulated by glucose is evident in this study though it warrants further research.

This study suggests that passage 1 MSCs with high glucose medium may be selected for further research on pancreatic islet development.

\section{Conclusion}

Glucose-stimulated the expression of surface marker CD24 in MSCs in a dose-dependent manner. Umbilical cord-derived MSCs isolated at passage 1 in a cell culture medium with high glucose concentration is ideal for research on pancreatic progenitors, pancreatic islets, targeted therapy, transplant, and artificial islet development.

\section{Acknowledgment}

This study was funded by ICMR-TSS.

\section{References}

1. Federation, ID: IDF Diabetes Atlas (2013) International Diabetes Federation: Brussels, Belgium, 2014.

2. Smukler S, Arntfield M, Razavi R, Bikopoulos G, Karpowicz P, et al. (2011) The adult mouse and human pancreas contain rare multipotent stem cells that express insulin. Cell Stem Cell 8: 281-293. [PubMed]

3. Bradley JA (2013) Transplant tolerance by treg therapy. Am J Transplant 14 5-6. [PubMed]

4. Efrat S (2008) Beta-cell replacement for insulin-dependent diabetes mellitus. Adv Drug Deliv Rev 60: 114-123. [PubMed]

5. Chao KC, Chao KF, Fu YS, Liu SH (2008) Islet-like clusters derived from mesenchymal stem cells in wharton's jelly of the human umbilical cord for transplantation to control type 1 diabetes. PLoS One 3: e1451. [PubMed]

6. Chen B, Zhou L, Wang L, Hu S, Wang R (2009) Better induction and differentiation strategy for rat pancreatic stem cells: transplant in liver niche. Transplant Proc 41: 3898-3904. [PubMed]

7. Chen $C$, Zhang Y, Sheng X, Huang $C$, Zang Y (2008) Differentiation of embryonic stem cells towards pancreatic progenitor cells and their transplantation into streptozotocin-induced diabetic mice. Cell Biol Int 32: 456-461. [PubMed] 
Citation: Rajendran R, Suman FR, Punnoose AM, Kuruvilla S, Krishnakumar S (2019) Effect of Glucose on the Expression of CD24 Marker in Umbilical Cord-Derived Mesenchymal Stem Cells. Stem Cell Res Ther 9: 444. doi: 10.4172/2157-7633.1000444

8. Chandra V, Swetha G, Muthyala S, Jaiswal AK, Bellare JR, et al. (2011) Isletlike cell aggregates generated from human adipose tissue derived stem cells ameliorate experimental diabetes in mice. PLoS One 6: e20615. [PubMed]

9. Buhring HJ, Battula VL, Treml S, Schewe B, Kanz L, et al. (2007) Novel markers for the prospective isolation of human MSC. Ann N Y Acad Sci 1106: 262-271. [PubMed]

10. Jiang W, Sui X, Zhang D, Liu M, Ding M, et al. (2011) CD24: A novel surface marker for PDX1-positive pancreatic progenitors derived from human embryonic stem cells. Stem Cells 29: 609-617. [PubMed]
11. Stolzing A, Coleman N, Scutt A (2006) Glucose-induced replicative senescence in Mesenchymal stem cells. Rejuvenation Res 9: 31-35. [PubMed]

12. Li YM, Schilling T, Benisch P, Zeck S, Meissner-Weigl J, et al. (2007) Effects of high glucose on mesenchymal stem cell proliferation and differentiation. Biochem Biophys Res Commun 363: 209-215. [PubMed]

13. Dhanasekaran M, Indumathi S, Rajkumar JS, Sudarsanam D (2013) Effect of high glucose on extensive culturing of mesenchymal stem cells derived from subcutaneous fat, omentum fat and bone marrow. Cell Biochem Funct 31: 2029. [PubMed] 